\title{
Potato Snacks in Bangladesh: Unhealthy Snack with Higher Fat Content and Alternative Healthier Options
}

\author{
Umme Aulia Munira ${ }^{1}$, Tasmia Tasnim ${ }^{1, *}$ \\ Department of Chemical Engineering, \\ Bangladesh University of Engineering \& Technology \\ E-mail:ummeamunira@gmail.com,tasmiatasnim@yahoo.com
}

\begin{abstract}
Potato snack is one of the most popular snacks item in Bangladesh. In this study the nutrition facts of potato snacks (potato chips and french fries) of different brands of home and aboard and of different food chain shops were analyzed and compared with the ideal one. From this study it was observed that most of the brands have been deviated from the quantity of nutrition facts that should be contained in an ideal potato snack. The noteworthy difference was noticed for the case of protein content for potato chips. For French fries, it has been determined that homemade french fries contain the lowest fat and carbohydrate. Since potato snacks are a source of harmful trans-fat, saturated fat and also high in calories, this paper has been discussed some healthier alternatives to this salty snack such as baked potato snack, using sugar solution and sweet potato.
\end{abstract}

\section{INTRODUCTION}

Potato chips and french fries are popular commonly eaten snack foods found around the world. They are known as chips, crisps and wafers depending on the area of the world. For sheer crispy, crunchy deliciousness, the potato chip is tough to beat. Potato chips are commonly served as an appetizer, side dish, or snack. The basic chips are cooked and salted; additional varieties are manufactured using various flavorings and ingredients including seasonings, herbs, spices, cheeses, and artificial additives. In Bangladesh potato is considered a high value crop with huge potential for both domestic and international market [1]. So it is cultivated widely in all districts of Bangladesh and for its availability potato snacks become a traditional snack food and favorite among all ages of Bangladeshi. Unfortunately, there definitely are some health drawbacks to this immensely popular food. Potato snacks are a calorie-dense, high-fat food. A new study by Harvard researchers suggests that potato chips lead to more weight gain per serving than any other food [2].

It is important to perform qualitative and quantitative analysis of the nutrition value of these potato snacks being eaten by Bangladeshi people to understand the health concern of this food. This paper will discuss the nutrition facts potato snacks of different brands have, as well as healthier alternatives to this salty snack.

\section{NUTRITION FACTS OF DIFFERENT BRANDED POTATO SNACKS}

Nutrition facts of various potato chips and french fries are tried to establish analytically here:

\subsection{Nutrition Facts of Different Branded Potato Chips}

Potato chips had, on average, a highly unbalanced nutritional composition being particularly biased towards excess of fat. They were also low in sugar, high in saturated fat and sodium, and low in protein, carbohydrate and fiber.

Some nutritionists have been showed that an ideal potato chip should have BNI (Balanced Nutrition Index) zero [3]. Here the nutrition fact of the ideal potato chip is shown in Fig. 1.

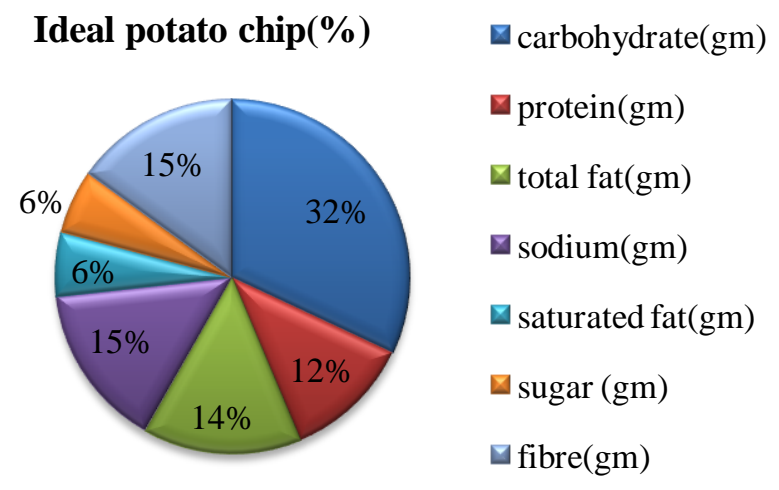

Fig. 1: Nutrition content of ideal potato chips.

Nutrition facts of different domestic and foreign branded potato chips are analyzed and compared with the ideal one for $100 \mathrm{gm}$ sample. Major nutrients i.e. carbohydrate, protein, fat content and energy content of different domestic and foreign branded potato chips that are used here are found from their individual manufacturing companies. Here comparison of carbohydrate, protein and energy are shown among several branded chips. The total fat content and Trans fat content of various branded chips are also shown in a stacked bar chart in Fig. 5.

\footnotetext{
* Corresponding Author: Tasmia Tasnim,

E-mail: tasmiatasnim@yahoo.com
} 


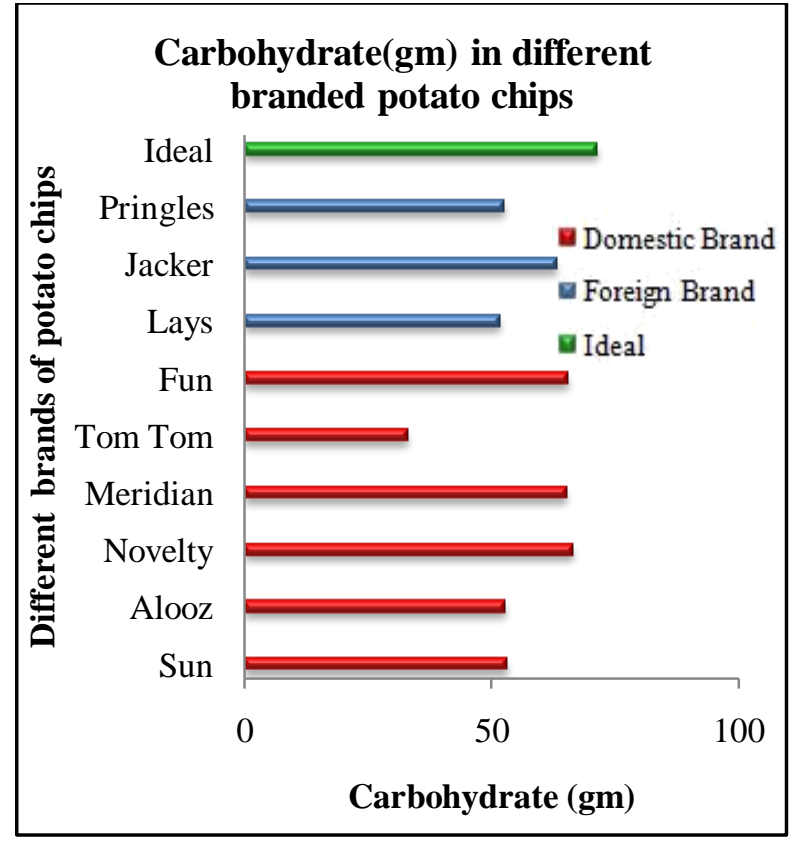

Fig. 2: Comparison of carbohydrate content of different branded potato chips.

It is shown in Fig. 2 that most of the brands contain carbohydrate content close to the ideal one while Tom Tom contains much lower carbohydrate content in it.

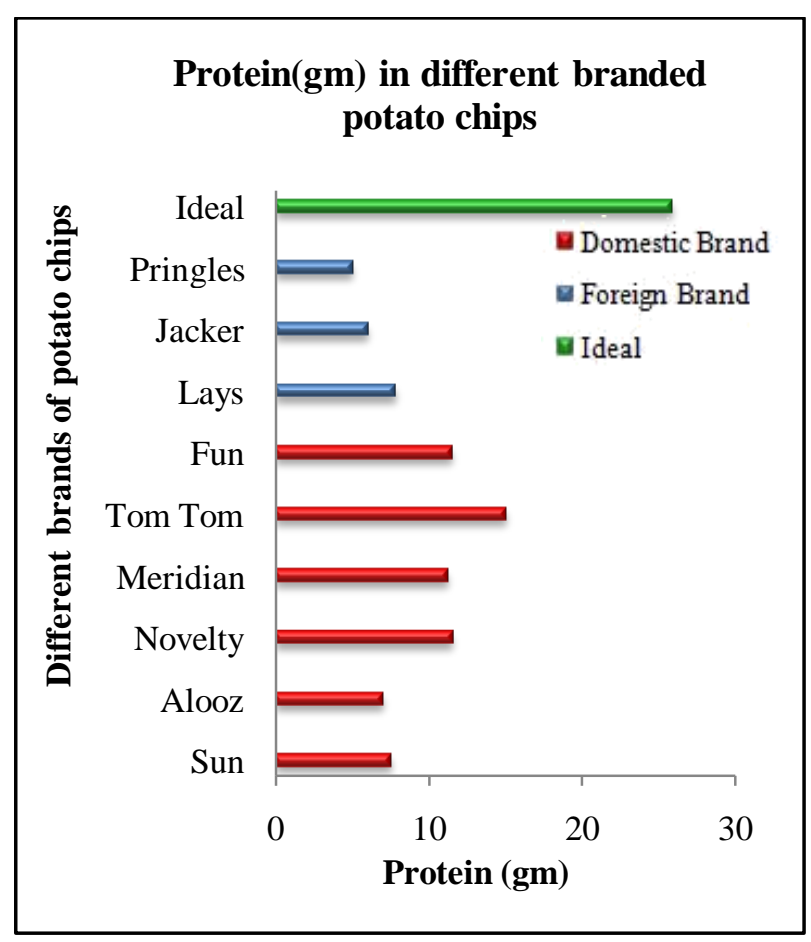

Fig. 3: Comparison of protein content of different branded potato chips.

From the above figure, it is seen that protein content of all the brands are much lower than the ideal one. Lack of protein is a significant health concern of this snack.
The observed brands contain not even half of the protein amount that a balanced index presents.

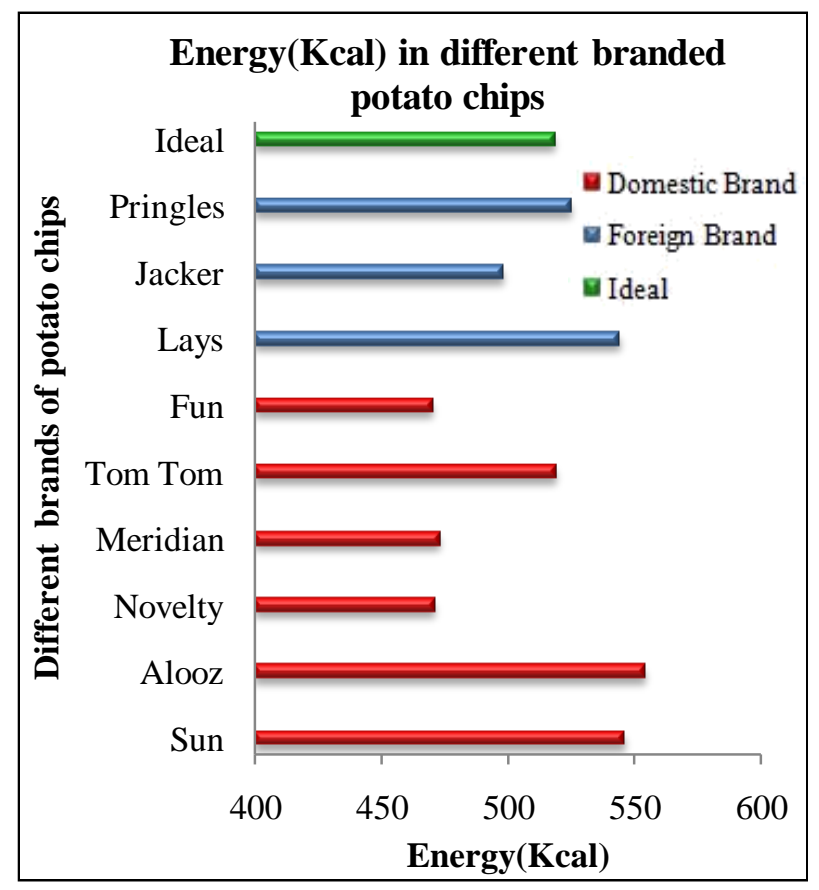

Fig. 4: Comparison of energy of different branded potato chips.

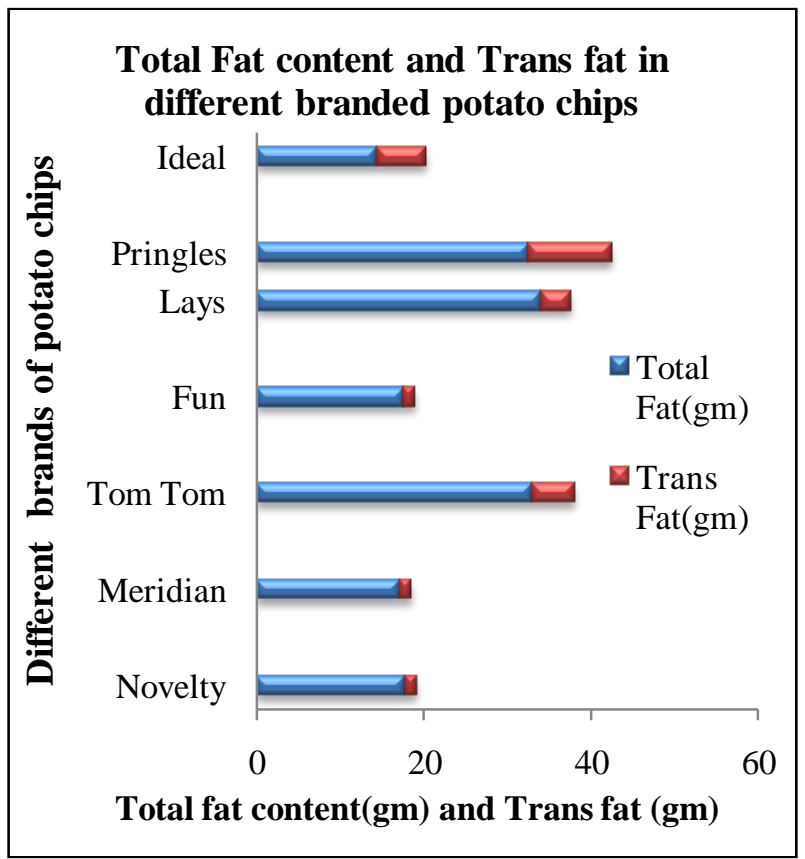

Fig. 5: Comparison of total fat and trans fat content of different branded potato chips.

Figure 4 and 5 exhibits that energy and fat content of most of the brands are almost same as ideal though Pringles, Lays and Tom Tom indicate higher fat content than the ideal snack must contain in it. 


\subsection{Nutrition Facts of Different Branded French Fries}

French fries are mainly consisting of carbohydrate and fat. Here in Table 1 calories, fat, carbohydrate and sodium content are shown for different foreign chain shops' french fries. In Fig. 6, fat and carbohydrate content are also compared among different chain shops', homemade and frozen french fries.

\subsubsection{Methodology}

Here alike potato chips, major nutrient contents and energy contents are found from their individual manufacturing chain shops[4,5]. For preparing homemade baked french fries the following methodology has been followed.

1. At first 3 russet potatoes, sliced into $1 / 4$ inch strips were taken.

2. Oven was preheated to $400{ }^{\circ} \mathrm{F}$ or $200^{\circ} \mathrm{C}$.

3. Potato strips were arranged in a single layer on a nonstick baking sheet, skin sides down and bakedfor 25 minutes in the preheated oven.

To compare the nutrition content of homemade French fries with the branded fries homemade sample was analyzed. Following procedures had been conducted to determine nutrition facts in baked potato snacks.

In determining fat content, at first, $5 \mathrm{gm}$ of the potato snacks was taken and then crushed by mortar and pestle. $15 \mathrm{ml}$ petroleum ether was added to the snacks and grinded the mixture thoroughly. Then the mixture was filtered with filter paperand the filtrate was left in a fume hood for 24 hours by which time the solvent had been evaporated. The weight of the remainder i.e. fat then measured.

Carbohydrates from potato fries $5 \mathrm{gm}$ of defatted sample was boiled with an $80 \%$ alcohol solution. Carbohydrates are soluble in alcoholic solutions, whereas proteins and dietary fiber are insoluble. The soluble components were separated from the insoluble components by filtering the boiled solution and collecting the filtrate (the part which passes through the filter) and the retentante (the part retained by the filter). These two fractions were then be dried and weighed to determine their concentrations. For the determination of sodium in French fries thermostatic titration procedure was used [6].

From the above figure, it is clear that homemade French fry is the lowest in carbohydrate and fat content. These are also rich in protein, sodium and potassium content and dietary fiber which have positive effect on health.
Table 1: Comparison of calories, fat, carbohydrate and sodium of different chain shops' and homemade french fries $[4,5]$.

\begin{tabular}{|l|c|r|r|r|r|}
\hline Company & $\begin{array}{c}\text { Servi } \\
\text { ng } \\
\text { Size }\end{array}$ & $\begin{array}{c}\text { Calo } \\
\text { ries }\end{array}$ & $\begin{array}{c}\text { Fat } \\
(\mathrm{g})\end{array}$ & $\begin{array}{c}\text { Carboh } \\
\text { ydrate } \\
(\mathrm{g})\end{array}$ & $\begin{array}{c}\text { Sodiu } \\
\mathrm{m}(\mathrm{g})\end{array}$ \\
\hline $\begin{array}{l}\text { Burger } \\
\text { King, } \\
\text { Value }\end{array}$ & $89 \mathrm{~g}$ & 240 & 10 & 34 & 330 \\
\hline $\begin{array}{l}\text { Burger } \\
\text { king, } \\
\text { Small }\end{array}$ & $128 \mathrm{~g}$ & 340 & 15 & 49 & 480 \\
\hline $\begin{array}{l}\text { Burger } \\
\text { King, } \\
\text { Medium }\end{array}$ & $153 \mathrm{~g}$ & 410 & 18 & 58 & 470 \\
\hline $\begin{array}{l}\text { Burger } \\
\text { King, } \\
\text { large }\end{array}$ & $190 \mathrm{~g}$ & 500 & 22 & 72 & 710 \\
\hline $\begin{array}{l}\text { McDonald } \\
\text { s Small }\end{array}$ & $71 \mathrm{~g}$ & 230 & 11 & 29 & 160 \\
\hline $\begin{array}{l}\text { McDonald } \\
\text { 's medium }\end{array}$ & $117 \mathrm{~g}$ & 380 & 19 & 48 & 270 \\
\hline $\begin{array}{l}\text { McDonald } \\
\text { 's large }\end{array}$ & $154 \mathrm{~g}$ & 500 & 25 & 63 & 450 \\
\hline $\begin{array}{l}\text { Wendy's } \\
\text { Small }\end{array}$ & $108 \mathrm{~g}$ & 320 & 16 & 42 & 350 \\
\hline $\begin{array}{l}\text { Wendy's } \\
\text { medium }\end{array}$ & $142 \mathrm{~g}$ & 420 & 21 & 55 & 460 \\
\hline $\begin{array}{l}\text { Wendy's } \\
\text { large }\end{array}$ & $176 \mathrm{~g}$ & 530 & 25 & 68 & 570 \\
\hline $\begin{array}{l}\text { Homemad } \\
\text { e, Baked }\end{array}$ & $107 \mathrm{~g}$ & 99 & 0 & 23 & 11 \\
\hline
\end{tabular}

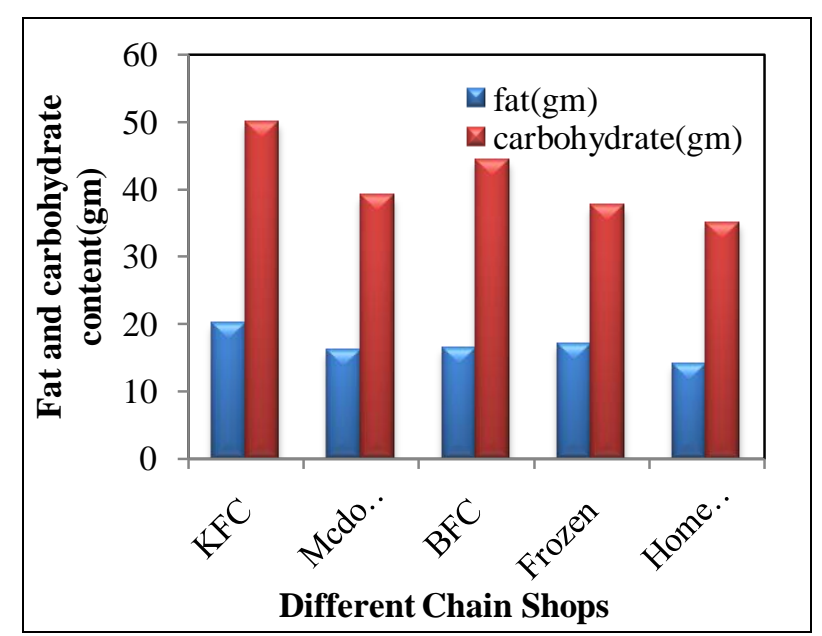

Fig. 6: Comparison of fat and carbohydrate content of different chain shops', frozen and homemade french fries.

\section{HEALTH CONCERNS}

Of course, there are plenty of health concerns with potato snacks. They are high in fat, particularly saturated fats. They are also high in calories, especially calories from fat. These calories are empty calories, meaning 
they do not provide any nutritional value. This information is just about the original flavored potato snacks; other flavors may contain more fat, calories, and sodium.

\section{FAT CONTENT IN POTATO SNACKS}

Trans fats, which are also known as partially hydrogenated oils, are created in a process that adds hydrogen to liquid vegetable oils to make them more solid. This allows for easier transportation and more uses. The American Health Association (AHA) notes that food companies like using trans fats because they are inexpensive and last a long time [6]. In addition to prolonging the shelf life of foods, trans fats give many snack foods a desirable taste and texture and flavor stability of foods. Many fast food restaurants use trans fats for frying because oils with trans fats can be used over and over in commercial fryers.

\subsection{Short-Term Effects of Trans Fats}

While scientists don't know exactly why, trans fats increase unhealthy cholesterol levels more than other types of fat. Trans fats raise the low-density lipoprotein, or bad cholesterol, and lower the high-density lipoprotein, or good cholesterol in the body, the AHA reports. Trans fats also increase levels of triglycerides, a type of fat in the blood, which may contribute to hardening of the arteries. Additionally, Trans fats promote inflammation and reduce the responsiveness of the cells lining blood vessels. It's also thought that eating foods with trans fats makes them more difficult to digest.

\subsection{Long-Term Effects of Trans Fats}

Over time, Trans fats can lead to clogged arteries. The University of Maryland Medical Center compares the negative effects of trans fats to what bacon grease does to a kitchen sink. Eating a diet high in trans fats for a long time clogs the pipes that feed your heart and brain. This can lead to a heart attack or stroke. Trans fats doubles the risk of heart disease, reports a Study. Trans fats have also been implicated in promoting obesity and raising the risk of developing diabetes.

\section{HEALTH BENEFITS}

Surprisingly, there are some health benefits to this incredibly popular junk food. There is no cholesterol in potato chips, which makes them different from many other kinds of savory snacks. Additionally, there is no sugar in potato chips, at least in the original flavored varieties. They are also a good source of polyunsaturated and monounsaturated fats, which contain important antioxidants and phytochemicals.

\section{HEALTHIER ALTERNATIVES}

\subsection{Baked Potato Snacks}

There are many healthy alternatives to unhealthy potato snacks. Baked potato chips are better to eat than original deep-fried potato chips. Since baked potato chips are baked rather than fried they are generally lower in calories, fats, and sodium. And they are all delicious. Nutrition content of baked chips (Lays) is shown in Fig. 7.

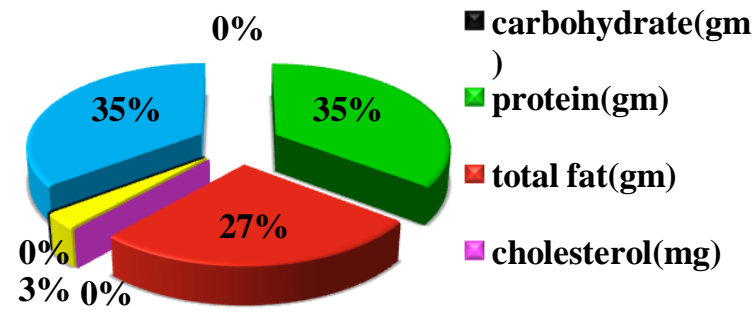

Fig. 7: Chart showing nutrition facts of baked lays.

Fig. 8 manifests that baked potato chips have lower carbohydrate and fat content which is why baked chips can be taken as a healthier option than the normal one.

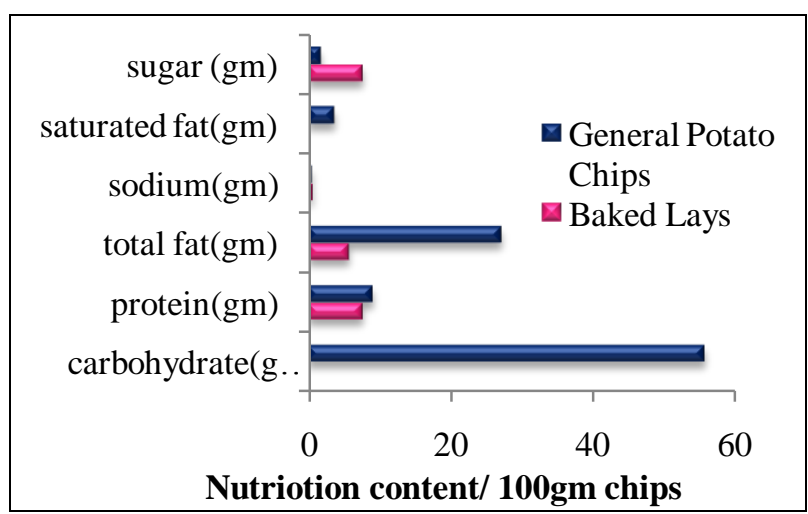

Fig. 8: Comparison between baked potato chips and original deep-fried potato chips

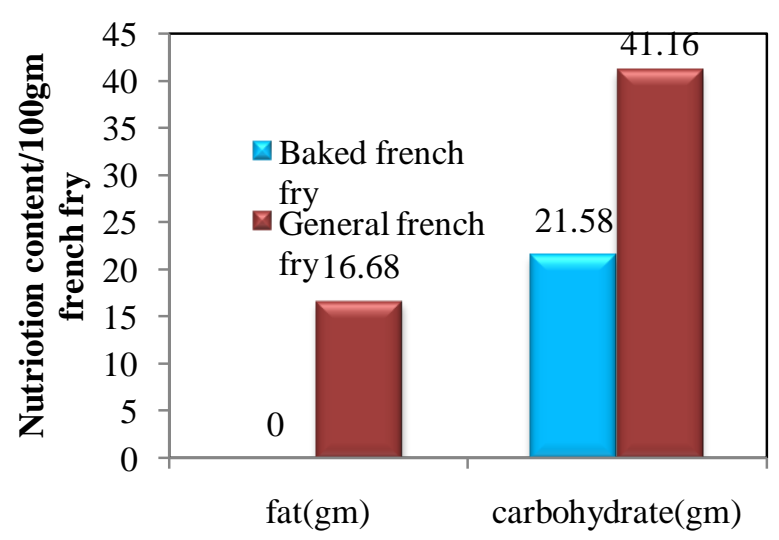

Fig. 9: Comparison between baked french fry and general deep-fried french fry. 
For baked french fry, it has been found out that baked french fry does not contain any fat and its carbohydrate content is almost half of the general deep-fried one.

In Fig. 9, comparison between baked and general deepfried french fry has been shown for fat and carbohydrate content.

\subsection{Pre-Drying and Dipping in Sugar Solution}

High oil content is a major factor affecting consumer acceptance of oil-fried products today and the low fat food products are becoming more popular. Various techniques have been applied to minimize the fat content of frying products. Pre-drying and subsequent dipping in a sugar solution before frying is an effective pre-treatment process to reduce oil content in the crisps $[7,8]$. The figure below depicts evidence of reduced oil content in pre-dried, sugar-dipped sample.

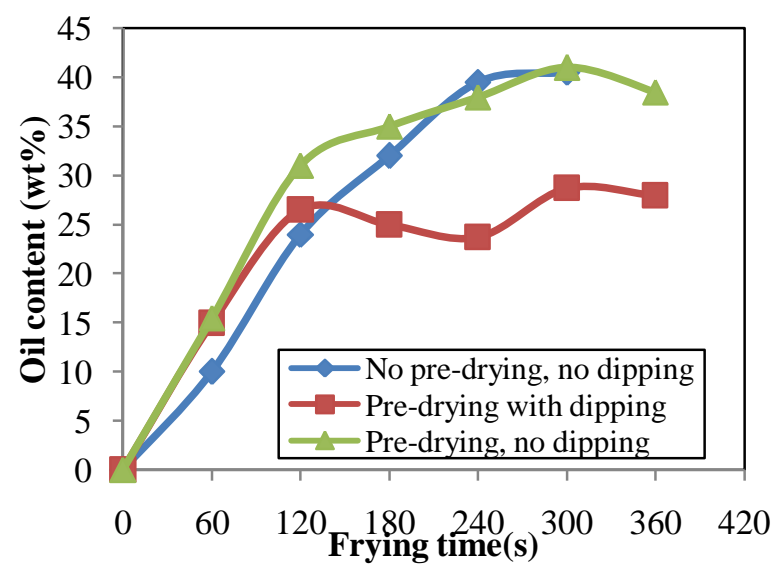

Fig. 10: Effect of pre-drying followed by sugar-dipping on the oil content of potato snacks during frying process.

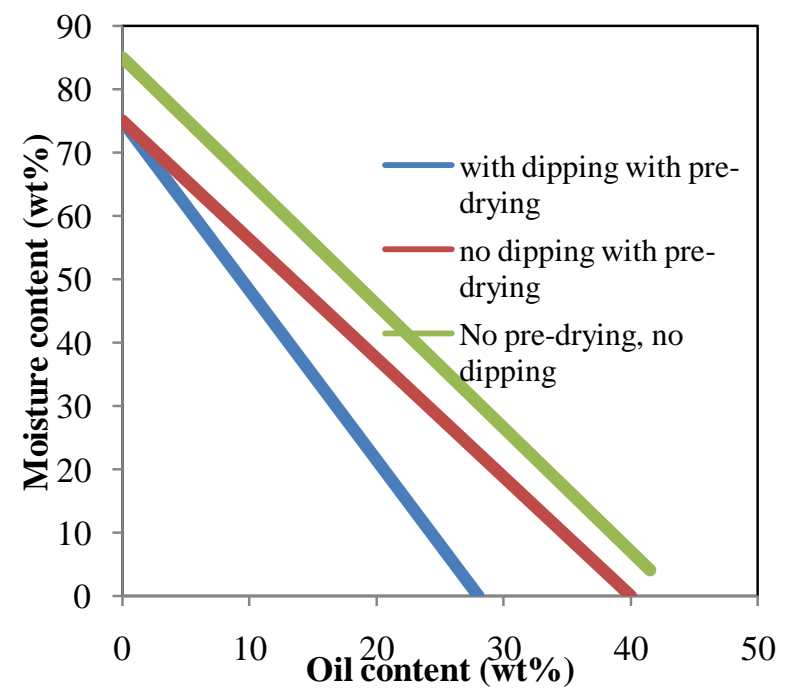

Fig. 11: Effect of pre-treatment on the relationship of oil uptake and moisture content.
This sugar-dipping process does not affect the final moisture content of the snacks. A linear relationship was found between the oil content and the moisture content of sugar-dipped potato snacks during frying.

\subsection{Sweet Potato Fries}

Sweet potato fries can be another alternative to the original potato snacks rich in fat. Packed with vitamin A and the essential mineral manganese, sweet potatoes make surprisingly tasty, crunchy, reduced-fat chips as well as French fry. They are most delicious when baked with a spice blend.

\section{CONCLUSIONS}

Choosing healthy snacks in reasonable portion can optimize energy level and manage hunger by providing regular fuel to the body and mind. Potato snacks can be a good source of nutrition facts in our country when the manufacturers follow the standard of nutrition value indicated by BNI in this popular light meal. Alternative healthier choices like baked potato fries and sweet potato fries should be recognized here. Some effective pre-treatments can be made during manufacturing potato snacks to extinguish the adverse effect of empty calories on the people of Bangladesh.

\section{REFERENCES}

[1] KATALYST, Contract Farming for Potato in the Northern Districts of Bangladesh.

[2] D. Mozaffarian, et al. "Changes in diet and lifestyle and long-term weight gain in women and men." New England Journal of Medicine 364.25 (2011): 2392-2404.

[3] Tasty Taytos, The Balanced Nutrition Index (ISSN 1177-8849), 2012, Issue 5.

[4] Mcdonalds 2013, Get nutrition, Mcdonalds, USA.

[5] Burger King 2012, Menu Nutrition Information, Burger King, USA.

[6] Jan Sheehan, Negative Effects of Trans Fats, 2011.

[7] Mai Tran, T. T., Xiao Dong Chen, and Christopher Southern. "Reducing oil content of fried potato crisps considerably using a 'sweet' pre-treatment technique." Journal of food engineering 80.2 (2007): 719-726.

[8] D. L. Miller, V. H. Castellanos, D. J. Shide, J. C. Peters, B. J. Rolls, Effect of fat free potato chips with and without nutrition labels on fat and energy intakes, The American journal of clinical nutrition 68.2 (1998): 282-290. 